\title{
An empirical analysis of the relationship between cost of control activities and project management success
}

\author{
Samiaah Al-Tmeemy ${ }^{1, *}$ and Bassam Al Bassam ${ }^{2}$ \\ ${ }^{1}$ Surveying Department, Technical Institute, Baquba, Iraq \\ ${ }^{2}$ Civil Engineering Department, Al Israa University College, Baghdad, Iraq
}

\begin{abstract}
To achieve the objectives of continuous improvement programs, construction managers must link the achievement of quality with cost. This paper aims to associate project management success (PMS) with cost of control (COC) activities in an empirical manner. Thus, the purpose is to determine the extent to which COC activities impact PMS. Quantitative method was adopted to collect data from Malaysian building companies using postal and email surveys. Hypothesis is tested using correlation and simple linear regression analysis. The findings of this study indicate that COC activities are positively associated with the PMS. The empirical evidences obtained from this research, provides financial justification for all quality improvement efforts. This can assist building contractors to enhance the success of project management by reducing the level of business failures due to poor quality, cost overruns, and delays.
\end{abstract}

\section{Introduction}

The objective of continuous improvement programs is not only to meet customer's requirements, but to do it at the lowest cost as well. Thus, to achieve the objectives of continuous improvement programs, construction managers must link the achievement of quality with cost $[1,2]$. This is because the achievement of quality target at a prohibitive cost is of little use [3]. In the same vein, downgrading quality to achieve competitive cost is equally inappropriate [3]. This linkage gives rise to cost of quality to be one of the most effective tools that harmonizes the economics of the company with product quality [4].

Quality costs are associated with two categories of quality-related activities: cost of control (COC) activities and cost of failure control (COFC) activities [5,6]. While $\mathrm{COC}$ refers to the cost of doing things right (i.e., prevention and appraisal costs), COFC comprises the cost of getting them wrong (I.e., failure cost). It must be remembered that $\mathrm{COC}$ are unavoidable costs that must be borne by the design and construction companies if their products/services are to be delivered right the first time [7]. On the other hand, COFC are almost avoidable in construction, as most originate from ineffective management practices [7]. However, quality improvements are often difficult for managers to justify and accept, mainly because the benefits are not always apparent from a strategic and economic perspective [8].
In general, any serious attempt to improve quality must take into account the costs associated with achieving quality [1,2]. Therefore, managers must employ more quantitative approaches to improve the clarity and precision of the relationship between $\mathrm{COC}$ and project management success (PMS).

Several studies showed the positive influence of COC activities on the level of quality and productivity improvement. However, limited research has been conducted to show conclusively the extent to which COC activities are important to project success. In addition, no research has been published to address the impact of quality control activities on project management success. The current research is concerned with the relationship between COC and PMS. Specifically, this research determines the extent to which the COC activities impact PMS in terms of adherence to budget, schedule, and quality target. According to AlTmeemy et al. [9], the PMS can be measured by three criteria; adherence to quality target, adherence to Budget and adherence to schedule .

Managing quality costs and understanding the relationships between these costs and project management performance is important to make better decisions related to improving project management performance and enhancing success. This relationship provides justification for increasing COC expenditures to improve the return on quality investments.

* Corresponding author: sam saf61@yahoo.com 


\section{Relationship between COC and PMS}

A critical factor in successful management of building projects is effective quality management [10]. A poor quality management system connotes that information gathering, reporting and management in a project become uncoordinated, thereby necessitating multiple redrawing and re-keying of information [7]. Ultimately, wasted time, unnecessary costs, increased errors and misunderstanding rework and non-conformance are accepted as inevitable features of the construction process [7,11-13]. Controlling quality costs leads to reduction in building cost and wasted time in correcting errors and rectifying failures. Thus, the greatest savings can be derived from reducing failure areas and minimizing defects. Therefore, implementing COC activities should improve quality which will ultimately mitigate costs through reduction in internal and external failure costs. Undeniably, reducing failure costs decreases wasted time and materials and such resources are spent prudently according to contract requirements. Eventually, orientations along the $\mathrm{COC}$ activities will have consequences for project management performance outcomes. Thus, the following hypothesis is proposed:

H1: There is a significant relationship between COC and PMS.

\section{Research methodology}

The main aim of this research is to establish empirically the extent to which COC activities impact PMS and each of its criteria. Hence, the positivist paradigm -appears to be the most suitable approach for this study, implying that the research approach of deductive reasoning must be used to derive a conclusion from a known premise. As this research adopts the positivist philosophy, the quantitative method was considered necessary for data collection. Meanwhile, a cross-sectional survey has been selected to gather data for the empirical study. A variety of statistical procedures were employed in data analyses, including descriptive statistics, goodness of measurements, correlation and regression.

The population was limited to contractors within Kuala Lumpur. The target respondents of this research were drawn from Construction Industry Development Board Malaysia (CIDB). According to CIDB statistics in 2008, there were 1196 active contractors involved in construction activities in Kuala Lumpur. Of this total, 594 contractors were chosen using stratified sampling method. The sample contained 95 contractors of G6 and 499 contractors of $\mathrm{G} 7$.

Data collected from the questionnaire survey was analyzed qualitatively. Various statistical procedures were used; these include descriptive statistics, validity and reliability, correlation and simple linear regression. Correlation refers to the strength of relationship between two or more variables [14]. Pearson's correlation coefficient is useful for determining the strength and direction of the association between two variables [15]. Therefore, Pearson's correlation coefficient was considered appropriate and thus, applied to assess the existence of relationships between COC and PMS.

Even though correlation is a useful research tool for examining the relationships between variables, this test has been noted to provide little information on the predictive power of the individual variables [15]. Nevertheless, regression analysis helps in exploring the effects of independent variable(s) on one dependent variable [16]. Therefore, regression analysis was applied to quantify the relative contribution of $\mathrm{COC}$ to enhance project management success.

As this research considers only one independent variable, a simple linear regression was used [17]. By applying simple linear regression with a single independent variable, the coefficient conveys how much the dependent variables are expected to increase (if the coefficient is positive) or decrease (if the coefficient is negative) when that independent variable increases by one.

To apply a valid regression model on the data several regression assumptions must be met [18]. Without verifying if the data have met the regression assumptions, results may become misleading. These assumptions represent the requirements of the underlying statistical theory [18] and a violation of any of these assumptions can affect the performance of the model [19]. The assumptions include: normality, linearity and homoscedasticity [18].

\section{Results and discussion}

\subsection{Response rate}

Of the 594 questionnaires dispatched to the selected sample, 153 were satisfactorily completed, pegging the total response rate at $25.7 \%$. This figure is acceptable according to Akintoye [20] and Dulaimi et al. [21]. Both of whom have stated that normal response rate in the construction industry for postal questionnaires is within the range of $20-30 \%$.

Frequency distribution is conducted to show four main profiles namely: educational level, age, occupation and period of experience as shown in Table 1. The General Respondents' Demographics (GRD) revealed that the majority of $(90.2 \%)$ held a Bachelor's degree as shown in Table 1. The highest frequency of respondents $(40.5 \%)$ was aged between $(40-49)$ years. Regarding the occupation of respondents, 'manager' position accounted for the largest percentage (55.6\%). Majority of 
respondents (96.1\%) had more than 10 years of experience.

Table 1. Descriptive Statistics of GRD.

\begin{tabular}{|c|c|c|c|c|}
\hline 胥 & Groups & 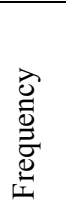 & 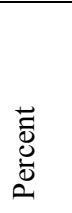 & 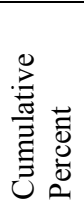 \\
\hline \multirow{4}{*}{ 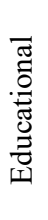 } & Diploma & 0 & 0 & 0 \\
\hline & Bachelor & 138 & 90.2 & 90.2 \\
\hline & Master & 13 & 8.5 & 98.7 \\
\hline & $\mathrm{PhD}$ & 2 & 1.3 & 100 \\
\hline \multirow{5}{*}{$\stackrel{\infty}{<}$} & $20-29$ yrs & 12 & 7.8 & 7.8 \\
\hline & 30-39 yrs & 59 & 38.6 & 46.4 \\
\hline & $40-49$ yrs & 62 & 40.5 & 86.9 \\
\hline & $50-59 \mathrm{yrs}$ & 10 & 6.5 & 93.5 \\
\hline & $60+y r s$ & 10 & 6.5 & 100 \\
\hline \multirow{6}{*}{ 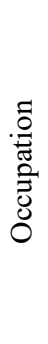 } & Quantity Survey & 5 & 3.3 & 3.3 \\
\hline & Project Engineer & 5 & 3.3 & 6.5 \\
\hline & Quality Control & 7 & 4.6 & 11.1 \\
\hline & Site Engineer & 41 & 26.8 & 37.9 \\
\hline & Manager & 85 & 55.6 & 93.5 \\
\hline & Director & 10 & 6.5 & 100 \\
\hline \multirow{5}{*}{ 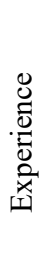 } & $5-9$ yrs & 6 & 3.9 & 3.9 \\
\hline & $10-14$ yrs & 37 & 24.2 & 28.1 \\
\hline & $15-19$ yrs & 25 & 16.3 & 44.4 \\
\hline & $20-24$ yrs & 60 & 39.2 & 83.7 \\
\hline & $25+\mathrm{yrs}$ & 25 & 16.3 & 100 \\
\hline
\end{tabular}

\subsection{The correlation}

The results in Table $2(\mathrm{r}=0.595, \mathrm{P}=0.000)$ offer strong support for accepting $\mathrm{H} 1$, which stated that COC is significantly associated with PMS. Therefore, the effective implementation of COC activities will enhance PMS. The project manager is responsible for delivering the project within the agreed time, cost and quality.

Table 2. Correlation between COC and PMS.

\begin{tabular}{|l|l|l|}
\hline & \multicolumn{1}{|c|}{ Correlation } & Sig. (2-tailed) \\
\hline PMS & $0.595^{*}$ & 0.000 \\
\hline * Correlation is significant at the 0.01 level (2-tailed). \\
\hline
\end{tabular}

\subsection{Simple regression analysis}

Regression can be used to discover whether the coefficients on the independent variables are truly different from zero. This indicates that independent variables actually have an effect on dependent variables, or alternatively, any apparent differences from zero are merely due to random chance [18]. The relationship between independent and dependent variables is expressed in the form of an equation. This equation yields a predicted or fitted value of dependent variable for each value of independent variable in the data set, holding all other factors fixed. The dependent and independent variables are entered in the proposed model in a linear way. However, the relationship between the variables is not necessarily linear [18].

Table 3: Regression Analysis Results for COC and PMS

\begin{tabular}{|c|c|c|c|c|c|}
\hline \multicolumn{6}{|c|}{ Model Summary of PMS } \\
\hline Corr. $\mathrm{R}$ & 0.595 & & \\
\hline R Square & 0.354 & \multicolumn{3}{|c|}{$\mathrm{F}$} & 82.880 \\
\hline $\begin{array}{c}\text { Adjusted R } \\
\text { Square }\end{array}$ & 0.350 & \multicolumn{3}{|c|}{ Sign. F } & 0.000 \\
\hline St. Error & 1.4092 & & & & \\
\hline \multicolumn{6}{|c|}{ Coefficients } \\
\hline Variable & B & $\begin{array}{l}\text { Std. } \\
\text { Error }\end{array}$ & Beta & $\mathrm{t}$ & Sig. \\
\hline $\mathrm{COC}$ & 0.291 & 0.032 & 0.595 & 9.104 & 0.000 \\
\hline (Constant) & 3.205 & 1.148 & & 2.791 & 0.006 \\
\hline
\end{tabular}

The results of this study are in line with those of previous studies [22-24] that supported the philosophy of "zero defect" (i.e., 100\% conformance to contracted requirements). These studies confirmed that $\mathrm{COC}$ implementation is the most important factor for eliminating failure and adhering to quality target in building projects. The findings likewise strengthen the suggestions offered by Abdul-Rahman et al. [25], who stated that almost all construction-related nonconformances could be avoided either by timely inspections or by the use of more experienced and skilled employees. Moreover, the results are consistent with the finding of Winner et al. [26], who reported that scrap and rework can be reduced by $75 \%$ through product and process design optimization. The findings of this study are also in line with Chong and Low [27], who claimed that most of defects in buildings were preventable by implementing $\mathrm{COC}$ activities to ensure better design, better workmanship, better materials and better maintenance.

The value of $\mathrm{R}^{2}$ for the generated model is 0.354 (Table 3 ), implying that COC accounts for $35.4 \%$ of the variation in PMS. The value of $R^{2}$ is close to the value of adjusted $\mathrm{R}^{2}$, indicating that the model can be generalized with shrinkage only by $0.4 \%$. The result for ANOVA 
shows a significant $F$ statistic $(F=82.880, p=0.00)$ at 0.01 level. This result indicates that the regression model is statistically significant.

The $\mathrm{t}$ test for COC is significant at 0.01 level $(\mathrm{t}=9.104$, $p=0.00$ ), as shown in Table 3 . Therefore, the null hypothesis is rejected and the alternative hypothesis, which states that coefficient $\mathrm{B}$ is significantly different from zero, is accepted. This indicates that COC implementation has a significant impact on PMS. The B coefficient of 0.291 indicates that PMS is predicted to increase by $29 \%$ units when COC increases by one unit. This relationship can be expressed by the following equation:

$$
\mathrm{PMS}=3.205+0.291 \mathrm{COC}
$$

This model expresses a static relationship and the optimum point will vary according to the nature of the project and environment. Nevertheless, it must recognize the dynamics of changing quality costs over time. It has been noticed that the level of COC expenditures appears to have no immediate impact on internal failure costs [4,28-30]. This is because of the time lag between cause and effect [28], as well as COC's positive correlation with internal failure costs in subsequent months [29]. The increase in COC, over a longer timeframe, continuously decreases failure costs and improves quality levels; subsequently, investment in COC yields a permanent reduction in failure costs in the total amount of COQ. Recognizing these dynamics, the objective is not to determine the optimal level of COC, but to link the identified process improvements through implementation of $\mathrm{COC}$ activities and enhancement of PM success through adherence to cost, schedule and quality target.

In construction projects, the timing of implementation of quality management is important [31]. Hendrickson [32] claimed that the decisions regarding quality should be made during the preliminary stages of construction and the design and planning stages. He added that during these preliminary stages, the component configurations, material specifications and functional performance are decided. Abdul-Rahman [31] shared the same point of view when he asserted that quality management should start from the inception up to the commission stages. The earlier implementation of quality management in a project is, the more likely problems can be recognized and savings realized. Abdul-Rahman [31] further explained that at the beginning of a project, the cost of non-conformance is nil and the main contractor/project manager should exploit the situation by implementing sound planning, anticipating problems and difficulties, and building trust between work contractors. Love and Irani [7] likewise asserted that COC must be borne by design and construction organizations if their products/services are to be delivered right the first time.

\section{Conclusions}

This study indicates that COC activities significantly enhance PMS. Consequently, PMS is expected to be affected positively by the implementation of COC activities; specifically, PMS is predicted to increase by $29.1 \%$ when COC increases by one unit.

This study provides knowledge and evidence that investment of resources in improving quality could be justified by the dramatic improvement in return on quality investments. This knowledge would enhance the awareness of contractors, managers, engineers and site workers on the importance of COC, providing a unique opportunity to better understand the extent to which the implementation of COC activities can impact PMS. This awareness can enlighten all concerned parties of the significance of COC in eliminating and preventing quality-related problems at an early stage. Subsequently, the company is able to establish a culture of commitment to perform the work correctly at the first time. Without a doubt, this culture will assist in reducing the level of project failure and lead to project management success.

The research has achieved its aim of investigating the relationship between COC activities and PMS and determining the extent to which these activities impact project management success. However, some limitations of this study are worth mentioning, as explained in the following sections. The first limitation is that this research is confined to building construction within Kuala Lumpur, and exclusive focus is placed on the top two grades of construction companies (i.e., G6 and G7). It is possible that different viewpoints may be found among other respondents, such as same-grade companies in other parts of Malaysia. Therefore, the results obtained may not be representative of the population of Malaysian construction and the situation in the rest of the world. However, the results have indicated that the models can be generalized to the population with bias of $0.0 \%-0.6 \%$.

The second limitation is that this research uses Juran's model where the appraisal and prevention costs are combined into COC, as it is difficult to decide which activities stand for prevention of quality failures since almost everything is well-managed [33]. However, it is well known that the two costs of appraisal and prevention maintain different behaviors and implications for cost control. Therefore, they are supposed to be considered separately.

The third limitation is that the main concern of this study is on COC and not COFC. Limitation on time and resources, COC was mainly focused in this study. In fact, the COFC helps to identify the improvement opportunities and focus on areas of high expenditure and wastage. Subsequently, this will contribute to PMS. Moreover, the relationship between COC and PMS is 
dynamic; therefore, it is expected that this relationship will change over time.

The limitations outlined above indicate several aspects where there is potential for improvement in the construction building industry. As an extension to this study, additional studies are needed to assess more accurately the effect of implementation of $\mathrm{COC}$ activities on PMS over time. For further studies, it would be interesting to take into account the effect of tracking and recording the failure cost on the performance of the construction projects. An evaluating and reporting quality failure cost is perceived as a useful indicator of project performance and provides opportunities for quality improvements and cost reduction.

\section{References}

1. Abdelsalam, H.M.E.and Gad, M.M. International Journal of Project Management 27, 501-511 (2009).

2. Schiffauerova, A. and Thomson, V. International Journal of Quality \& Reliability Management 23, 647669 (2006b).

3. Hall, M. and Tomkins, C. Construction Management and Economics 19, 727-740 (2001).

4. Chang, C. Journal of the Academy of Business and Economics II, 172-187 (2005).

5. Hansen, D.R.and Mowen, M.M. (Thomson, SouthWestern, United State of America, 2006).

6. Feigenbaum, A.V. Total quality control (McGrawHill Inc., New York, 1983).

7. Love, P.E.D.andIrani, Z. Information and Management 40, 649-461 (2003).

8. Czuchry, A.J., Yasin, M.M.and Ltle, G.S. Industrial Management \& Data Systems 99, 362-366 (1999).

9. Al-Tmeemy, S.M.H.M., Abdul-Rahman, H.andHarun, Z. International Journal of Project Management 29, 337-348 (2011).

10. Achi, F.O., Onukwube, H.N. and Oluwaseyi M, Atlanta USA, 2007).

11. Abdul-Rahman, H. Construction Management and Economics 13, 23-32 (1995).

12. Alwi, S., Keith, H.and Sherif, M. Asia Pacific Building and Construction Management Journal 6, 2-6 (2001).

13. Smallwood, J.and Rossouw, J.-H. in (COBRA ) (Dublin, Ireland 2008).

14. Bewick, V., Cheek, L.andBall, J. Critical Care 7, 451-459 (2003).

15. Field, A. Discovering (Sage Publications Ltd, London, 2000).

16. Kerlinger, F.N.andLee, H.B. (Harcourt College Publishers, Orlando, 2000).

17. Tabachnick, B.G.and Fidell, L.S. (Pearson Education Inc., United States of America, 2007).

18. Hair, J.F., Black, W.C., Babin, B.J.and Anderson, R.E. Multivariate Data Analysis (Pearson Prentice Hall, New Jersey, 2010).
19. Wang, G.C.S.andJain, C.L. (Graceway Publishing Company, Inc., New York, 2003).

20. Akintoye, A. Construction Management and Economics 18, 77-89 (2000).

21. Dulaimi, M.F., Ling., F.Y.Y.and Bajracharya, 21, 307-318 (2003).

22. Crosby, P.B. (McGraw-Hill, New York, 1979).

23. Kazaz, A., Birgonulb, M.T.and Ulubeylia, S. 40, 1356-1365 (2005).

24. Low, S.P.and Yeo, H.K.C. International Journal of Quality \& Reliability Management 15, 329-349 (1998).

25. Abdul-Rahman, H., Thompson, P.A.and Whyte, I.L. International Journal of Quality \& Reliability Management 13, 48-60 (1996).

26. Winner, R.I., Pennell, J.P., Bertrand, H.E. and Slusarczuk, M.M. (Institute for Defense Analyses, Alexandria, Virginia, 1988).

27. Chong, W.-K.andLow, S.-P. Journal of Performance of Constructed Facilities 20, 213-221 (2006).

28. Campanella, J. and Corcoran, F.J. (ASQC Quality Press, Milwaukee, WI, 1983).

29. Ittner, C. Operations Research 44, 114-130 (1996).

30. Love, P.E.D., Mandal, P.andLi, H. Determining the causal structure of rework in construction projects. Construction Management and Economics 17, 505-517 (1999).

31. Abdul-Rahman, H. International Journal of Quality \& Reliability Management 14, 464-281 (1997).

32. Hendrickson, C. (Prentice Hall, Pittsburgh, 2000).

33. Aoieong, R.T., Tang, S.L.and Ahmed, S.M.A Construction Management and Economics 20, 179-192 (2002). 